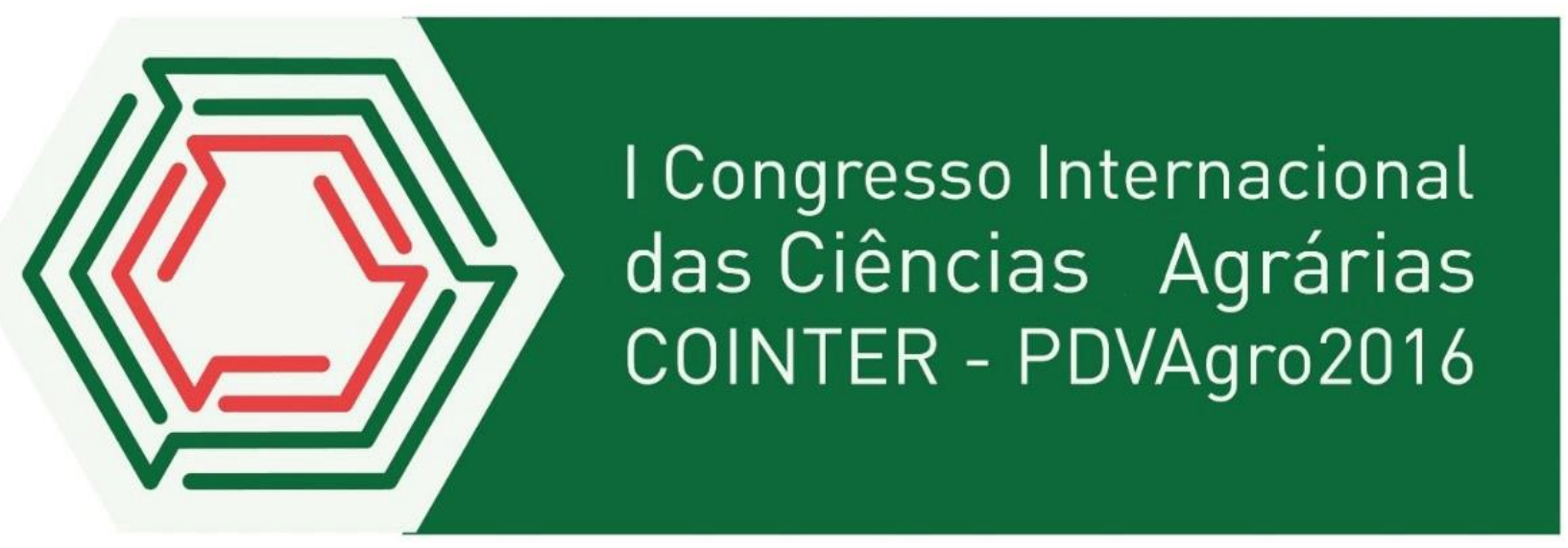

\title{
AVALICAÇÃO DAS CONDICÕES HIGIÊNICO-SANITÁRIAS EM ESTABELECIMENTOS COMERCIALIZADORES DE VEGETAIS NA CIDADE DE VITÓRIA DE SANTO ANTÃO
}

\author{
Apresentação: Pôster
}

Cleidiane Maria dos Santos ${ }^{1}$; Djalma Vitorino Costa Filho² ${ }^{2}$ Cristiane Ayala de Oliveira ${ }^{3}$

\section{Introdução}

A segurança alimentar é tida como um conceito primordial nas indústrias, comércios, estabelecimentos de alimentos, pois garante, desde o recebimento da matéria-prima até a comercialização do produto sua inocuidade e qualidade nutricional. A busca por alimentos seguros, cada vez mais está inserida na mesa do consumidor brasileiro, pois a garantia, a todos, de condições de acesso a alimentos básicos de qualidade, em quantidade suficiente de modo permanente e sem comprometer o acesso a outras necessidades básicas com bases em práticas alimentares que possibilitem a saudável reprodução do organismo humano, contribuindo, assim, para uma existência digna.

\section{Fundamentação Teórica}

Os serviços de alimentação estão incluídos, de acordo com o Instituto Brasileiro de Geografia e Estatística - IBGE (2013), naqueles prestados principalmente às famílias. É a atividade com maior proporção de companhias nesse segmento da economia e também a que mais emprega,

\footnotetext{
11 Tecnologia em Alimentos, Instituto Federal de Educação, Ciência e Tecnologia do Sertão Pernambucano Campus Salgueiro, E-mail: cleidianeleao88@gmail.com

22 Tecnologia em Alimentos, Instituto Federal de Educação, Ciência e Tecnologia do Sertão Pernambucano Campus Salgueiro, E-mail: djalma.vitorino@vitoria.ifpe.edu.br

33 Tecnóloga em Agroindústria, Instituto Federal de Educação, Ciência e Tecnologia do Sertão Pernambucano - Campus Salgueiro, E-mail: crisayalatecnologia@gmail.com
} 
com 13,5\% do total de pessoas ocupadas. Entre 2007 e 2013, o número de estabelecimentos relativos a alimentação cresceu 40,7\%. A necessidade de estabelecer critérios e práticas norteando a qualidade nos serviços de alimentação, fez a Agência Nacional de Vigilância Sanitária - ANVISA, estabelecer no ano de 2002 e 2004, respectivamente, a Resolução de Diretoria Colegiada no 275 de 21 de outubro de 2002, que dispõe o Regulamento Técnico de Procedimentos Operacionais Padronizados aplicados aos Estabelecimentos Produtores/Industrializadores de Alimentos e a Lista de Verificação das Boas Práticas de Fabricação em Estabelecimentos Produtores/Industrializadores de Alimentos (BRASIL, 2002) e a Resolução de Diretoria Colegiada no 216 de 15 de setembro de 2004, que dispõe o Regulamento Técnico de Boas Práticas para Serviços de Alimentação (BRASIL, 2004). Em busca de um processo produtivo com base em legislações sanitárias, o programa de qualidade de Boas Práticas de Fabricação - BPF, prevê a avaliação da estrutura física e do pessoal envolvido a manipulação, beneficiamento e industrialização de alimentos. Mais detalhadamente, busca a higienização das edificações, das instalações, equipamentos e utensílios, controle da qualidade da água utilizada, os vetores transmissíveis de doenças e pragas, higiene e saúde dos manipuladores, manejo de resíduos e controle da garantia dos alimentos preparados (SILVA JUNIOR, 2002).

O programa de BPF, é indispensável para a obtenção de alimentos higiênicos e seguros. De acordo com a Portaria 368/97, do Ministério da Agricultura, Pecuária e Abastecimento, as BPF's são normas e procedimentos exigidos na elaboração de produtos alimentícios para o consumo humano. Refere-se às medidas a serem tomadas pelos estabelecimentos que trabalham com elaboração de alimentos, para garantia da qualidade sanitária e conformidade vigente (BRASIL, 1997). Em Pernambuco, o município de Vitória de Santo Antão, destaca-se pela distância entre a capital pernambucana, a cerca de $50 \mathrm{~km}$, fazendo com que, a inserção de novos empreendimentos torne-se viáveis a sua implementação na cidade. Dentre esses estabelecimentos, pode-se dizer que os serviços de alimentação ganham destaque, com a fábrica da BRF Brasil, a Mondelez International e a Nissin-Ajinomoto, no município circunvizinho de Glória do Goitá-PE. Portanto, objetivou-se avaliar as condições higiênico-sanitárias de estabelecimentos comercializadores de vegetais na cidade de Vitória de Santo Antão-PE.

\section{Metodologia}

A avaliação das boas práticas de fabricação de estabelecimentos comercializadores de vegetais do município de Vitória de Santo Antão, no Estado de Pernambuco, no período de Junho de 2016. Foi utilizada como ferramenta de avaliação do estabelecimento, um guia de verificação ou 
check-list da RDC 275 de 21 de outubro de 2002 do Ministério da Saúde, que é um instrumento de medição de qualidade. Os avaliadores do trabalho foram até os locais de avaliação e aplicaram o check-list. A aplicação foi realizada através de observações nos próprios locais e preenchimento da lista de um dia de trabalho nos estabelecimentos.

O check-list constitui de 162 itens de verificação que avalia: estrutura física, condições higiênicas sanitárias do estabelecimento, saúde do manipulador, controle dos Procedimentos Operacionais Padronizados, controle do processo, controle tempo e temperatura, contaminação cruzada, controle de transporte do alimento, armazenamento dos alimentos e manual de boas práticas. As opções de respostas para o preenchimento do check-list eram: sim, não e não se aplica (N.A.). Os estabelecimentos foram classificados como: Grupo 1 - de 76 a 100\% de atendimento dos itens; Grupo 2 - de 51 a $75 \%$ de atendimento dos itens e Grupo 3 - 0 a 50\% de atendimento dos itens.

\section{Resultados e Discussões}

A implantação de um sistema de garantia de qualidade em unidades que utilizam matériaprima de origem vegetal torna-se imprescindível. Pois o fato se justifica, uma vez que esses alimentos estão sujeitos a diversas fontes de contaminação microbiana ao longo do seu processamento, como manipuladores, instalações, equipamentos e utensílios, água entre outros (CRUZ; CENCI; MAIA, 2006). Os resultados foram obtidos através da aplicação do check-list de acordo com a RDC 275/2002.

1.Tabela de resultados da lista de verificação dos estabelecimentos; Fonte Própria

\begin{tabular}{|c|c|c|c|c|c|c|c|c|}
\hline BLOCOS & & ITENS & N.S.A $(*)$ & $\%$ & SIM & $\%$ & NÃO & $\%$ \\
\hline $\begin{array}{l}\text { EDIFICAÇÕES } \\
\text { INSTALAÇÕES }\end{array}$ & $\mathrm{E}$ & 78 & 2 & 2,64 & 56 & 73,68 & 18 & 23,68 \\
\hline EQUIPQMENTOS & & 21 & 0 & 0 & 14 & 66,66 & 7 & 33,34 \\
\hline MANIPULADORES & & 14 & 0 & 0 & 10 & 71,42 & 4 & 28,58 \\
\hline $\begin{array}{l}\text { PROD. E TRANS. } \\
\text { ALIMENTOS }\end{array}$ & $\mathrm{DE}$ & 33 & 0 & 0 & 27 & 81,81 & 6 & 18,19 \\
\hline DOCUMENTAÇÃO & & 16 & 0 & 0 & 0 & 0 & 16 & 100 \\
\hline
\end{tabular}


Dos 78 itens para edificações e instalações foram obtidos 56 SIM, com um percentual de 73,68 \% de adequação, resultado superior apresentado por Neves (2014), onde o diagnóstico indicou que, as instalações tiveram menos de 50,00\% de adequações, sendo que pisos, paredes e teto das áreas de produção estavam em adequado estado de conservação, mas não higienizados corretamente, além de ausência de ralos sifonados, luminárias sem proteção, instalações sanitárias desorganizadas, lavatórios com torneiras sem acionamento automático, inexistência de produtos destinados à higiene pessoal e recipientes de lixo sem tampas.

O bloco equipamentos correspondeu a $66,66 \%$ das conformidades, pois superfícies de contato, equipamentos e utensílios que entram em contato direto com o alimento durante a sua preparação podem se tornar focos de contaminação, principalmente quando não forem submetidos a processos de higienização adequados e eficientes. Dados sugerem que cerca de $16 \%$ dos surtos de Doenças Transmitidas por Alimentos - DTA's, sejam causados por utensílios e equipamentos contaminados (BUENO et al., 2012). Chesca et al. (2003), avaliaram o grau de contaminação em uma Unidade de Alimentação e Nutrição - UAN. Eles encontraram 90\% dos equipamentos e utensílios oferecendo risco de contaminação aos alimentos e 100\% das amostras de alimentos analisadas encontravam-se fora dos padrões legais estabelecidos pela legislação.

No quesito manipuladores os resultados foram de $71,42 \%$, valor positivo em comparação ao estudo em que Neves et al. (2014) encontrou menos de 50,00\% de adequações para manipuladores e higiene pessoal, sendo encontrados também manipuladores sem uniformes completos. Em diferentes micros e pequenas empresas produtoras de polpas de frutas 70,59\% afirmaram que os colaboradores utilizavam uniformes padronizados e 73,0\% afirmaram que trabalham providos de EPI (LOPEZ, 2008).

$O$ item com maior índice de conformidade foi produção e transporte de alimentos conferindo $81,81 \%$, o transporte é feito em câmaras climatizadas até o final da comercialização. O pior índice apresentado no estabelecimento foi para Documentação, uma empresa avaliada por Tramontin e Silva (2012), também apresentou percentual de 100\% para os itens não conformes relacionados à documentação.

\section{Conclusões}

A aplicação de ferramentas investigativas, como o da RDC 275, de 21 de outubro de 2002, nos mostra o quão necessário é a segurança alimentar, como essencial meio específico de garantia da saúde do consumidor. Numa época em que os parâmetros de qualidade dos alimentos e 
segurança à saúde do consumidor são decisórios na escolha de um produto, as unidades beneficiadoras de alimentos, devem estar mais atentas em garantir qualidade em suas atividades desenvolvidas. De acordo com o estudo, foi observado que no item documentação, os estabelecimentos estão $100 \%$ em desacordo com a legislação vigente, necessitando assim, medidas urgentes que assegurem a ação corretiva. Para tanto, os serviços de alimentação se enquadram no grupo (2), onde atingiram 66,06\% de conformidade com a ferramenta investigava RDC 275.

\section{Referências}

BRASIL, Portaria n 368/97. Regulamento Técnico Sobre as Condições Higiênico-Sanitárias e de Boas Práticas de Fabricação para Estabelecimentos Elaboradores / Industrializadores de Alimentos. Brasília: M.A.A., 1997. Publicado no Diário Oficial da União de 08/09/1997, Seção 1, Página 1997.

Ministério da Saúde. Agência Nacional de Vigilância Sanitária (ANVISA). Resolução RDC nº. 275, de 21 de outubro de 2002. Dispõe sobre Regulamento Técnico de Procedimentos Operacionais Padronizados aplicados aos Estabelecimentos Produtores/Industrializadores de Alimentos e a Lista de Verificação das Boas Práticas de Fabricação em Estabelecimentos Produtores/Industrializadores de Alimentos. Disponível em: http://www.anvisa.gov.br/. Acesso em: 20 de Agosto de 2016.

- Ministério da Saúde. Agência Nacional de Vigilância Sanitária (ANVISA). Resolução RDC n. 216, de 15 de setembro de 2004. Dispõe sobre o regulamento técnico de boas práticas para serviços de alimentação. Disponível em: http://www.anvisa.gov.br/. Acesso em: 21 de Agosto de 2016.

BUENO, S. M.; LOPES, M. R. V.; GRACIANO, R. A. S.; FERNANDES, E.C. B.; GARCIACRUZ, C. H. Avaliação da qualidade de polpas de frutas congeladas. Revista do Instituto Adolfo Lutz, v. 61, n. 2, p. 121-126, 2002.

CHESCA, A.C. et al. Equipamentos e utensílios de unidades de alimentação e nutrição: um risco constante de contaminação das refeições. Rev. Higiene Alimentar, São Paulo, v.17, n. 114/115, p.20-23, nov. / dez. 2003.

CRUZ, AG; CENCI, AS; MAIA, MCA. Pré-requisitos para implementação do sistema Appcc em uma linha de alface minimamente processada. Ciênc. Tecnol. Aliment. Campinas, 26 (1): 104-109, jan. Mar. 2006.

INSTITUTO BRASILEIRO DE GEOGRAFIA E ESTATÍSTICA - IBGE - Alimentação concentra $20 \%$ das empresas no setor de serviços, nota IBGE, 2015. Disponível em: http://www.valor.com.br/brasil/4237816/alimentacao-concentra-20-da-empresas-no-setor-deservicos-nota-ibge. Acesso em: 27 de agosto de 2016. 
LOPES, R. M.; SILVA, J. P.; VIEIRA, R. F.; SILVA, D. B; GOMES, I. S.; AGOSTINI-COSTA, T. S. Composição de ácidos graxos em polpa de frutas nativas do cerrado. Revista Brasileira de Fruticultura, Jaboticabal, v. 34, n. 2, p. 635-640, 2012.

SILVA Jr. Manual de controle higiênico-sanitários em alimentos. 5. ed. São Paulo: Ed. Varela, 2002. 397 p. 